\title{
O022. Migraineurs: seriously ill or basically healthy?
}

\author{
Alessandro Panconesi ${ }^{*}$, Maria L Bartolozzi, Leonello Guidi \\ From Abstracts from the 1st Joint ANIRCEF-SISC Congress \\ Rome, Italy. 29-31 October 2015
}

\section{Background}

Some epidemiological studies report many comorbidities in migraine, mostly identified through questionnaires and based on self-reported diagnosis [1]. Pharmacoepidemiological studies have also identified some comorbidities. We evaluated the migraine comorbidities using and comparing data derived by different methods of study, with the aim of minimizing the variability of results.

\section{Materials and methods}

We evaluated prospectively the prevalence of some comorbidities in the first 1,000 migraine patients (aged 15-65 years), classified according to the IHS diagnostic criteria, presenting to the Headache Center (HC) in the period 2011 to 2013 and resident in the district of the Empoli Health Authority (HA11). In addition to a detailed semistructured face to face interview, health information was researched in the database of specialist visits, hospitalization or the Emergency Department. Drug prescription rates of the HA11 pharmaceutical database (PD) of 155,829 residents aged $15-65$ years were also analyzed, as were the subgroup of 1,108 triptan users.

To increase the strength of the study, the data was compared to a large database of Health Search (HS) of the Research Institute of the Italian Society of General Practice, to which general practitioners contributed with shared modalities for the regular and complete recording of the principal health data [2].

\section{Results}

In our clinical survey (780 females, 220 males; mean age 39.5 years; 866 episodic migraine, 134 chronic migraine) the prevalence of treated diseases were: depression $5.6 \%$, hypertension, $9.3 \%$, diabetes $1.2 \%$,

* Correspondence: a.panconesi@usl11.toscana.it

Headache Center, Department of Neurology, Health Authority 11, Empoli, Italy

\section{SpringerOpen ${ }^{\circ}$}

C 2015 Panconesi et al. This is an Open Access article distributed under the terms of the Creative Commons Attribution License (http://creativecommons.org/licenses/by/4.0), which permits unrestricted use, distribution, and reproduction in any medium, provided the original work is properly cited. The Creative Commons Public Domain Dedication waiver (http://creativecommons.org/ publicdomain/zero/1.0/) applies to the data made available in this article, unless otherwise stated. asthma $3.3 \%$, hypotiroidism $6.4 \%$, hypertiroidism $0.3 \%$, hypercholesterolemia $0.5 \%$. These percentages are not superior to drug prescription rate found in the PD in the general population. A higher prescription rate for some chronic diseases was found in triptan users in comparison with the general population and migraine patients (HC), but this may be due to drugs also used in migraine prevention.

The HS database, covering 893,870 subjects aged 14-85 years, showed an increased percentage of depression (20.0 vs 5.5 ) and hypotiroidism (6.1 vs 3.7 ) in migraine patients, but not of hypertension or diabetes [2].

This was the first study on migraine comorbidities utilizing three different accurate databases (HC, PD, HS), within the same country. Our study does not confirm that many of the comorbidities reported are associated with migraine, in particular those involved in cardiovascular risk. The contrasting evidence in the literature could be due to the bias intrinsic in the method of study: group, age not comparable, sex differences, marker drugs used off label, and uncertainness of diagnosis.

Written informed consent to publication was obtained from the patient(s).

\section{Published: 28 September 2015}

\section{References}

1. Le $\mathrm{H}$, et al: Co-morbidity of migraine with somatic disease in a large population-based study. Cephalalgia 2011, 31:43-64.

2. , http://simg.it/documenti/aree_cliniche/Neurologica/congressi/ FUMAGALLI_Cefalea_HS.pdf.

doi:10.1186/1129-2377-16-S1-A66

Cite this article as: Panconesi et al:: 0022. Migraineurs: seriously ill or basically healthy? The Journal of Headache and Pain 2015 16(Suppl 1):A66.

\section{Conclusions}

